\title{
TRENDS IN COVERING DIFFERENT ASPECTS OF ANATOMY IN WRITTEN UNDERGRADUATE MBBS COURSE
}

\author{
Ayub $\mathrm{M}^{1}$, Habib $\mathrm{MA}^{2}$, Huq $\mathrm{AKMF}^{3}$, Manara $\mathrm{A}^{4}$, Begum $\mathrm{N}^{5}$, Hossain $\mathrm{S}^{6}$
}

\begin{abstract}
Introduction: Rapid advancement of biomedical knowledge along with consistent increase in technical facilities in medical science changes the teaching-learning processes of undergraduate medical course in many countries and Anatomy is no exception. Some of these changes have been incorporated into the undergraduate medical course in Bangladesh and some are yet to be incorporated. In this situation, a thorough understanding is required to know how different aspects of Anatomy are distributed in terms of weightage in the written assessment of Anatomy course, which indirectly influence the learning of the course. To have an insight regarding this, thorough analyses of recent question papers of two universities were done in this study.
\end{abstract}

Objectives: Analyses of question papers give a clue about the variation in the distribution of weightage in different aspects of Anatomy in the undergraduate written exams (due to absence) in terms of allocation of proper weightage in the curriculum.

Study design: A descriptive, observational study involving quantitative analysis.

Place and period of study: Anatomy Department of AFMC from March 2012 to August 2012.
Materials and Methods: The study includes analysis of 28 short answer question papers and 23 multiple choice question papers of two universities in Dhaka. This is a quantitative study and means of percentage value were calculated by using SPSS program for analyzing the question paper.

Results: It is observed from the analyses that Topographic Anatomy got maximum coverage (40-89\%) and aspects like Genetics, Radiographic

Anatomy and Surface was covered less than 3\% (absent in some question papers) of the question papers. The result of the present study will help in improvement of present written assessment system of the undergraduate Anatomy course.

Conclusion: From result and analysis it is evident that the present assessment system needs to give proper weightage to different aspects of Anatomy to make the assessment more valid, objective and reliable.

Key-Words: Undergraduate anatomy, written examinations, coverage

1. Lt Col Mahmuda Ayub, MBBS, M Phil, Asst Prof of Anatomy, AFMC, Dhaka Cantt. 2. Col Md Ahsan Habib, MBBS, M Phil, Prof of Anatomy, AFMC, Dhaka Cantt. 3. Lt Col AKM Faizul Huq, MBBS, Graded Spl in Medicine, CMH, Dhaka Cantt. 4. Lt Col Anju Manara, MBBS, MS, Asst Prof of Anatomy, AFMC, Dhaka Cantt. 5. Lt Col Nasrin Begum, MBBS, M Phil, Asst Prof of Anatomy, AFMC, Dhaka Cantt. 6. Lt Col Sharmin Hossain, MBBS, M Phil, Asst Prof of Anatomy, AFMC, Dhaka Cantt. 


\section{Introduction}

Medical education has changed enormously in last few decades and it has to deal with more and more information. So medial educators, around the world are involved in making necessary updates in the undergraduate curricula to increase the competency of future physicians (for practice). Anatomy is an integral part of undergraduate medical curriculum and it is the structural basis of life. As an essential part of undergraduate medical education, teaching-learning and assessment of Anatomy has gone through remarkable changes in recent years in developed countries. Some positive developments have been made in the Anatomy course in terms of teaching-learning and assessment system in Bangladesh by adopting a new curriculum $^{1}$ in 2002. But proper implementation of the learning objectives set in the curriculum is yet to be established.

A regional approach has been taken in studying Anatomy in this curriculum and it is followed by different public and private universities. In this approach human body is divided into six regions e.g. thorax, abdomen, upper limb, lower limb, head and neck region and central nervous system and eyeball. Reputed universities around the world differ in their preference while choosing between systemic and regional approach. Drake et $\mathrm{al}^{2}$ mentioned four types of approach that can be followed:

1. Traditional (regional)

2. Systemic

3. Combined traditional and systemic

4. Problem-based

In the new curriculum1 teaching-learning of Regional Anatomy (different "cards") involves lecture, tutorial and demonstration classes and dissection hours. Although regional approach is emphasized, other aspects of Anatomy like Developmental Anatomy, Histology, etc. also have specific allocated time in the form of lecture, tutorial, practical and demonstration classes in this curriculum $^{1}$ and systemic approach has been taken for studying these aspects of Anatomy. The main change in teaching strategy is that weight has shifted towards increased proportion of tutorial and practical classes.

Reforms are also done in the assessment system in the form of introducing structured oral examination, objective structured practical examinations and the contents of written examinations are clearly mentioned in "Module on the 1st Professional MBBS Examination system to be held in January 2008 based on New Curriculum ${ }^{3}$. Short Answer Questions (SAQs) and Multiple Choice Questions (MCQs) are recommended in the written exams. Problem is that the contents are clearly outlined, but weightage for different aspects of Anatomy are not mentioned. So examiners will differ in their opinion in giving weightage to different aspects of Anatomy. This may create marked subjectivity in the written exams affecting as a whole the present assessment system. The present study was done to find out the coverage of different aspects of Anatomy in every portion of written examination question of undergraduate Anatomy course of Dhaka University (DU) and Bangladesh University of Professionals (BUP).

\section{Materials and Methods}

\section{Method of division of Anatomy in different aspects}

For the purpose of the study, Anatomy is divided into several different aspects as per the curriculum $^{1}$ as much as possible. So Anatomy was considered under the following subheadings.

1. General and Systemic Anatomy

2. Cell Biology

3. Genetics

4. Topographical (Regional) Anatomy

5. Histology - which is considered under two headings - General and Systemic

6. Developmental Anatomy-which is considered again under two headings - General and

Systemic

7. Neuroanatomy

8. Surface Anatomy

9. Anatomy of Imaging (Radiographic Anatomy) 10. Clinical Anatomy 


\section{Regional Anatomy}

Considers the organization of the human body as major parts or segments e.g., main body consisting of head, neck and trunk \& paired upper limb \& lower $\operatorname{limb} b^{4}$. In this study, after considering the region, topics like formation/parts, location, gross anatomical relations, blood supply, and lymphatic drainage of the organ or structure were included under Topographic Anatomy.

In the curriculum ${ }^{1}$, 6 th card is the central nervous system \& eyeball. In this study, eyeball is considered under head \& neck region for the purpose of the study \& Neuroanatomy includes nervous system and nerve supply to the organs, muscles and skin $^{5}$. In case of central nervous system, it is considered under following aspects: Topographic Anatomy, Systemic Developmental Anatomy, Systemic Histology, and Clinical Anatomy

Surface Anatomy - deals with the relationships of deeper structures to the surface of the body ${ }^{6}$.

Clinical Anatomy - emphasizes aspects of bodily structure \& function important in the practice of medicine, dentistry and allied health sciences ${ }^{4}$. It should be clarified that any topics like questions on non-disjunction and mutation which indicates Cell Biology \& Genetics respectively, but in this study were considered under Clinical Anatomy. This is maintained in analyzing every aspect of Anatomy.

Radiographic Anatomy-is the study of structure of the body that includes use of $\mathrm{x}$-rays ${ }^{7}$.

\section{Materials for analyses of question papers}

Two first professional examinations are held in each year. Seven examinations per university, from January 2009 to January 2012, total $(7 \times 2)$ fourteen examinations, were targeted for this study. There are two question papers per examination and each paper has questions under Group A and Group B. Each group has separate short answer questions (SAQ) and multiple choice questions (MCQ) portions. The contents of each group are clarified in Module ${ }^{3}$ 2008. Questions of every group are carefully observed to have an insight about the distribution of different aspects of Anatomy in the question papers.
All the available Anatomy (SAQ) question papers of the First Professional MBBS examinations of both Dhaka University (DU) and Bangladesh University of Professionals (BUP) held from January 2009 to January 2012 were collected for analysis and total twenty eight (28) short answer question papers were analyzed.

MCQ questions of January 2012 of Dhaka University were not available. So analyses of MCQ questions of January 2012 of both universities were excluded from the study. Also question Paper-1 MCQ portion of January 2009 of Dhaka University was not available to the researcher, so analysis of this question paper was also excluded from the study. So total twenty three (23) multiple choice question papers were analyzed.

Operational definitions related to the analyses question papers

Each portion (SAQ or MCQ) of the question paper was subdivided into following components ${ }^{5}$.

\section{Item}

The term 'item' was used to denote each numbered question asked in the question papers. So there are total fourteen (seven in each Group) items in the SAQ portion and twenty (ten in each Group) items in the MCQ portion of each question paper.

\section{Part}

The term 'part' was used to denote each separate sentence in each short answer questions (SAQ).

\section{Segment}

The term 'segment' indicates each component of a 'part' of an SAQ that called for a different answer from the examinee. The term 'segment' was used for each individual branch of a multiple choice question (MCQ).

"Classify surface epithelium with examples. Give structure and functions of mitochondria". In this question, the whole question is 'item'. In each group, SAQ portion has seven questions termed as 'item' and in MCQ portion there is ten.

"Classify surface epithelium with example" indicates a sentence, so it was considered as 'part' and this question is called for two different answers, "classification" and "example", hence each one denotes as 'segment' 


\section{Method used for the analyses of question papers}

There were seven (7) items in each group of SAQ portion and ten (10) 'item's in the MCQ portion. As each question paper has two groups, so each question paper had fourteen (14) items in SAQ portion and twenty (20) 'item's in MCQ portion.

Thus as a whole in SAQ portion total 392 items were analyzed. Each item had one or more parts. Thus a total 933 parts were analyzed. Each part again comprised of one or more segments. Thus a total 1245 segments were analyzed. In MCQ portion thus 460 items and 2300 segments were analyzed.

The results were obtained by quantitative analysis of the question papers by calculating percentage value with SD by using SPSS.

\section{Results}

It is depicted from Table-1 that more or less than $30 \%$ questions were on topics like General \& Systemic Anatomy, General Developmental Anatomy, and General Histology in both universities in case of both MCQ and SAQ papers. On the other hand, less than 5\% questions were on Clinical Anatomy, Neuroanatomy, Genetics and Radiographic Anatomy in both SAQ and MCQ papers of both universities.

Table-I: Frequencies of coverage of different aspects of Anatomy in Paper-I of Group-A portion questions (both MCQs and SAQs) of the First Professional MBBS written exams of two universities (DU and BUP)

\begin{tabular}{lll}
\hline \multirow{2}{*}{ Aspects of Anatomy } & MCQ & SAQ \\
\cline { 2 - 3 } & $\begin{array}{l}\text { Percentage frequency } \\
\text { of coverage } \pm \text { SD } n=550\end{array}$ & $\begin{array}{l}\text { Percentage frequency } \\
\text { of coverage } \pm \text { SDn }=\mathbf{3 2 0}\end{array}$ \\
\hline Cell Biology & $9.5 \pm 7.78$ & $16.59 \pm 0.74$ \\
*Genetics & $(55)$ & $(53)$ \\
General and & $2.5 \pm 3.54$ & $1.88 \pm 2.52$ \\
Systemic Anatomy & $(15)$ & $(06)$ \\
General Developmental & $27.17 \pm 1.65$ & $24.74 \pm 1.31$ \\
Anatomy & $(150)$ & $(79)$ \\
GeneralHistology & $26.67 \pm 4.72$ & $20.29 \pm 0.77$ \\
& $(145)$ & $(65)$ \\
Neuroanatomy & $4.84 \pm 4.48$ & $(1.69 \pm 3.56$ \\
& $(25)$ & $3.73 \pm 0.62$ \\
Clinical Anatomy & $0(0)$ & $(12)$ \\
Radiographic Anatomy & $0.90(05)$ & $1.19 \pm 1.68$ \\
\hline
\end{tabular}

(Figures in the parenthesis indicate number of segments)
* No questions on Genetics in Dhaka University both in MCQ and SAQ

Tables and figures show questions on Topographic Anatomy were maximum in all regions both in SAQ and MCQ papers (especially in central nervous system, thorax, upper and lower limbs). From further observations it was evident that Clinical Anatomy got negligible coverage in MCQ papers addressing all the regions and that was more or less than $15 \%$ in SAQ portion of all regions. Surface Anatomy questions (MCQ and SAQ) were present in thorax and abdomen (both in MCQ and SAQ and MCQ portion of upper limb respectively) and got less than $2 \%$ coverage and it is also found that one fifth questions (SAQ) were on Systemic Developmental Anatomy in abdomen and head and neck region including eyeball and those were absent in upper and lower limbs. Similarly one fourth questions (SAQ) were on Systemic Histology in abdomen and in other regions that was less than $10 \%$ (both in SAQ and MCQ). Near about one fifth questions were on Neuroanatomy in the limbs whereas in other regions that was more or less than $10 \%$.

Table-II: Frequencies of coverage of different aspects of Anatomy in MCQ's addressing thorax, abdomen, head and neck region including eyeball of the First Professional MBBS written exams of two universities (DU and BUP)

\begin{tabular}{|c|c|c|c|}
\hline \multirow{3}{*}{ Aspects of Anatomy } & \multicolumn{3}{|c|}{ Percentage frequency of coverage $\pm \mathrm{SD}$} \\
\hline & & Abdomen & $\begin{array}{l}\text { Head neck region } \\
\text { including eyeball }\end{array}$ \\
\hline & $\mathrm{n}=350$ & $n=410$ & $\mathrm{n}=\mathbf{2 8 5}$ \\
\hline Topographic Anatomy & $\begin{array}{l}78.02 \pm 15.27 \\
(272)\end{array}$ & $\begin{array}{l}69.26 \pm 7.30 \\
(285)\end{array}$ & $\begin{array}{l}72.70 \pm 3.25 \\
(208)\end{array}$ \\
\hline $\begin{array}{l}\text { Systemic Developmental } \\
\text { Anatomy }\end{array}$ & $\begin{array}{l}\text { l } 6.19 \pm 4.60 \\
(22)\end{array}$ & $\begin{array}{l}14.84 \pm 5.85 \\
(60)\end{array}$ & $\begin{array}{l}13.09 \pm 5.25 \\
(36)\end{array}$ \\
\hline Systemic Histology & $\begin{array}{l}4.81 \pm 2.63 \\
(17)\end{array}$ & $\begin{array}{l}7.0 \pm 1.93 \\
(29)\end{array}$ & $\begin{array}{l}3.39 \pm 1.4 \\
(10)\end{array}$ \\
\hline Neuroanatomy & $\begin{array}{l}9.04 \pm 5.3 \\
(32)\end{array}$ & $\begin{array}{l}6.64 \pm 1.49 \\
(27)\end{array}$ & $\begin{array}{l}10.43 \pm 1.17 \\
(30)\end{array}$ \\
\hline ClinicalAnatomy & $\begin{array}{l}0.55 \pm 0.78 \\
(02)\end{array}$ & $\begin{array}{l}0.47 \pm .66 \\
(02)\end{array}$ & $\begin{array}{l}0.4 \pm 0.57 \\
(01)\end{array}$ \\
\hline Surface Anatomy & $\begin{array}{l}1.39 \pm 1.97 \\
(05)\end{array}$ & $\begin{array}{l}1.8 \pm 2.54 \\
(07)\end{array}$ & $0(0)$ \\
\hline Radiographic Anatomy & $0(0)$ & $0(0)$ & $0(0)$ \\
\hline
\end{tabular}

(Figures in the parenthesis indicate number of segments) 
Table-III: Frequencies of coverage of different aspects of Anatomy in SAQ's addressing thorax, abdomen, head and neck region including eyeball of the First Professional MBBS written exams of two universities (DU and BUP)

\begin{tabular}{|c|c|c|c|}
\hline \multirow[b]{2}{*}{ Aspects of Anatomy } & \multicolumn{3}{|c|}{ Percentage frequency of coverage $\pm \mathrm{SD}$} \\
\hline & Thorax & Abdomen & $\begin{array}{l}\text { Head and neck region } \\
\text { including eyeball }\end{array}$ \\
\hline & $\mathrm{n}=162$ & $n=192$ & $n=190$ \\
\hline Topographic Anatomy & $\begin{array}{l}66.55 \pm 8.46 \\
(109)\end{array}$ & $\begin{array}{l}42.28 \pm 2.38 \\
(81)\end{array}$ & $\begin{array}{l}41.68 \pm 1.67 \\
(79)\end{array}$ \\
\hline $\begin{array}{l}\text { Systemic Developmental } \\
\text { Anatomy }\end{array}$ & $\begin{array}{l}7.84 \pm 4.86 \\
(12)\end{array}$ & $\begin{array}{l}16.22 \pm 1.93 \\
(31)\end{array}$ & $\begin{array}{l}21.8 \pm 2.83 \\
(41)\end{array}$ \\
\hline Systemic Histology & $\begin{array}{l}6.43 \pm 2.86 \\
(10)\end{array}$ & $\begin{array}{l}24.96 \pm 1.10 \\
(48)\end{array}$ & $\begin{array}{l}9.73 \pm 3.08 \\
(18)\end{array}$ \\
\hline Neuroanatomy & $\begin{array}{l}4.47 \pm 1.65 \\
(07)\end{array}$ & $\begin{array}{l}3.63 \pm 0.47 \\
(07)\end{array}$ & $\begin{array}{l}10.18 \pm 4.29 \\
(20)\end{array}$ \\
\hline ClinicalAnatomy & $\begin{array}{l}13.64 \pm 0.63 \\
(22)\end{array}$ & $\begin{array}{l}11.38 \pm 2.11 \\
(22)\end{array}$ & $\begin{array}{l}16.58 \pm 3.24 \\
(32)\end{array}$ \\
\hline Surface Anatomy & $\begin{array}{l}1.1 \pm 2.42 \\
(02)\end{array}$ & $\begin{array}{l}1.54 \pm 0.62 \\
(03)\end{array}$ & $0(0)$ \\
\hline Radiographic Anatomy & $0(0)$ & $0(0)$ & $0(0)$ \\
\hline
\end{tabular}

Figures in the parenthesis indicate number of segments

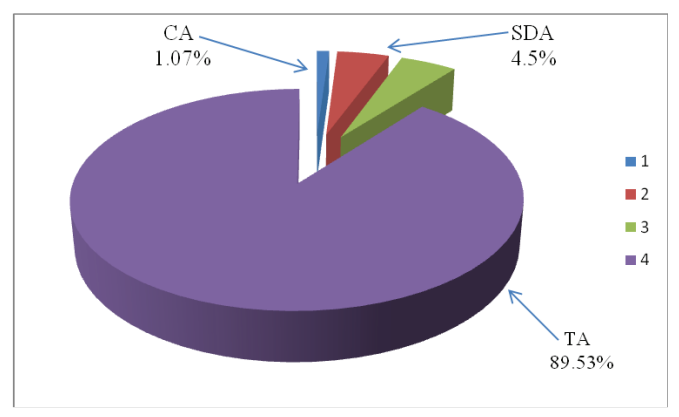

Fig-1a: Percentage frequency of distribution of different aspects of Anatomy dealing with central nervous system in MCQ's of both universities (DU and BUP)

Here numbers of segments were 265 and were distributed as follows:

Clinical Anatomy-03

Systemic Developmental Anatomy-12

Systemic Histology-13

Topographic Anatomy-237

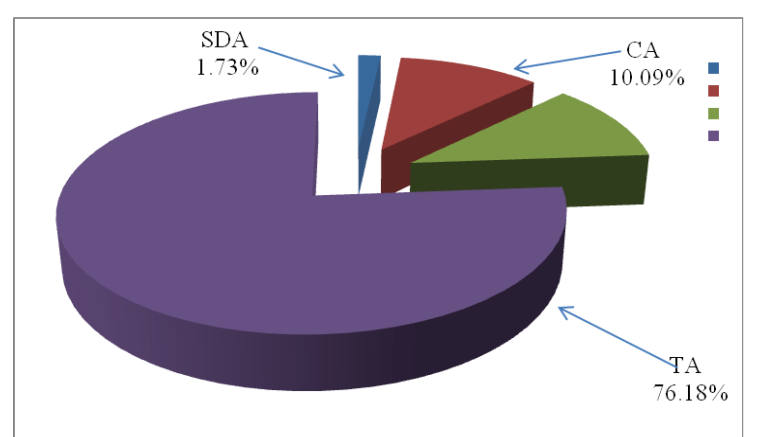

Fig-1b: Percentage frequency of distribution different of aspects of Anatomy dealing with central nervous system in SAQ's both universities (DU and BUP)

Here numbers of segments were 115 and were distributed as follows:

SDA--Systemic Developmental Anatomy -02

CA---Clinical Anatomy-12,

SH---Systemic Histology-13

TA---Topographic Anatomy-88

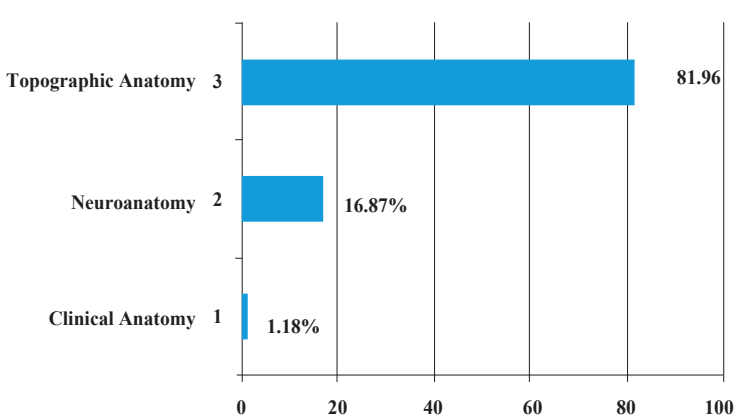

Fig-2a: Percentage frequency of distribution of different aspects of Anatomy addressing Inferior Extremity in MCQ's of both universities (DU and BUP)

Here numbers of segments were 190 and were distributed as follows:

Clinical Anatomy - 02

Neuroanatomy-34

Topographic Anatomy-154

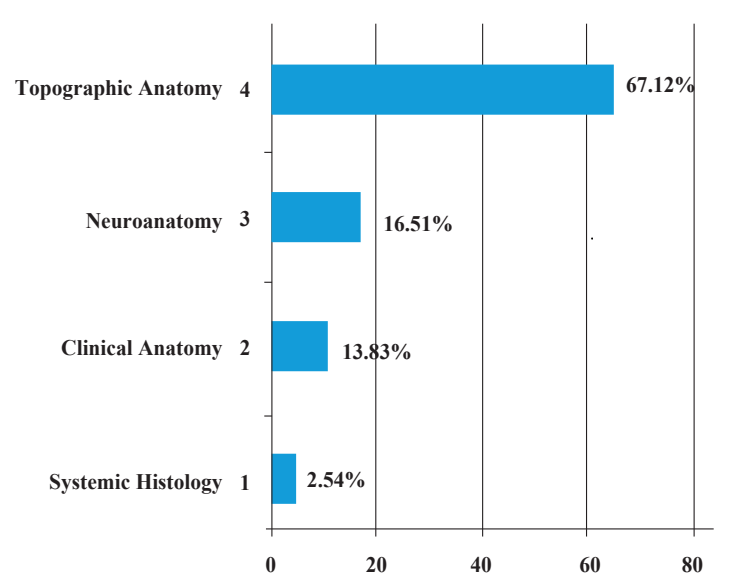

Fig-2b: Percentage frequency of distribution of different aspects of Anatomy of addressing Inferior Extremity in SAQ's of both universities (DU and BUP) 
Here numbers of segments were 115 and were distributed as follows:

Systemic Histology-03

Clinical Anatomy-16

Neuroanatomy-19

Topographic Anatomy—-77

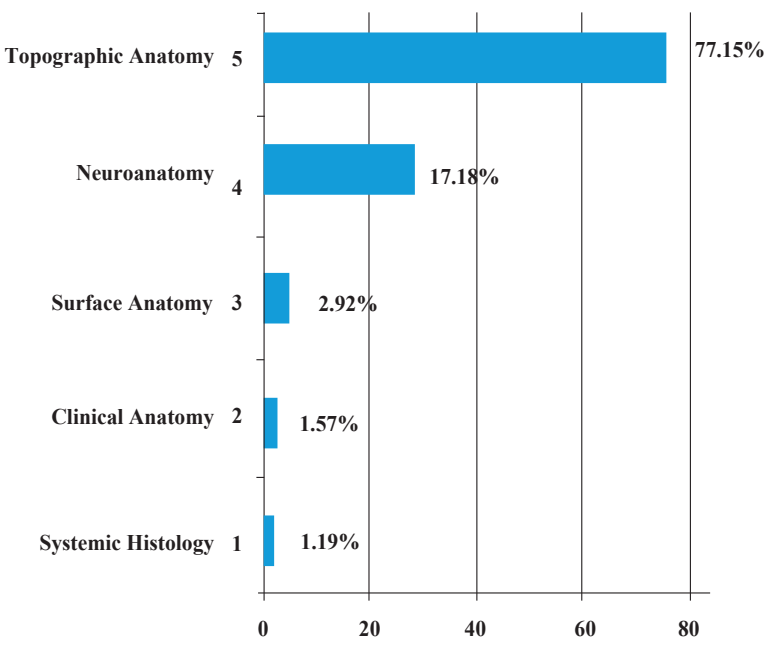

Fig-3a: Percentage frequency of distribution of different aspects of Anatomy addressing Superior Extremity in MCQ's of both universities (DU and BUP). Here numbers of segments were 250 and were distributed as follows:

Clinical Anatomy-04

Systemic Histology-13

Topographic Anatomy - 88

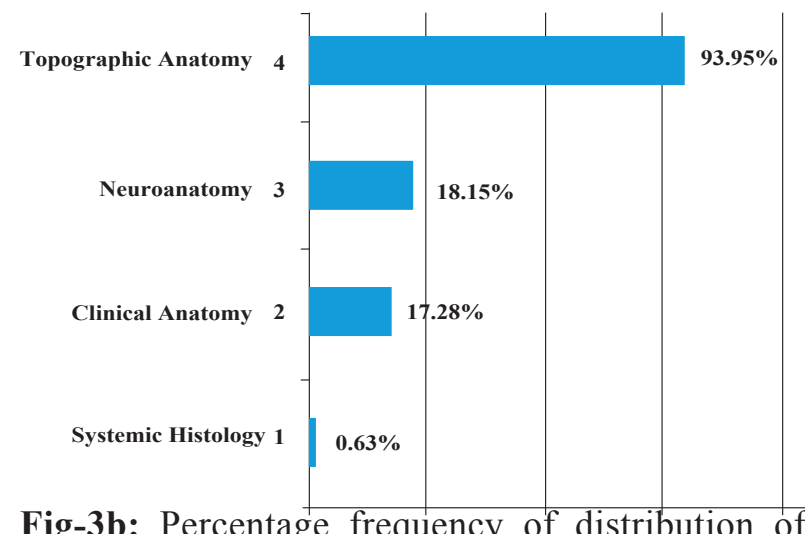

addressing Superior Extremity in SAQs of both universities (DU and BUP)
Here numbers of segments were 151 and were distributed as follows:

$$
\begin{aligned}
& \text { Systemic Histology-01 } \\
& \text { Neuroanatomy-26 } \\
& \text { Clinical Anatomy-27 } \\
& \text { Topographic Anatomy—97 }
\end{aligned}
$$

\section{Discussion}

Drake et $\mathrm{al}^{2}$. states that Anatomy includes those structures that can be seen macroscopically and microscopically ${ }^{2}$. Apart from these, Anatomy has got other dimension like Neuroanatomy, Surface Anatomy etc. Some are revealed with advent of newer technologies, like Radiographic Anatomy, Sectional Anatomy etc. All these are, however not separate entities. There is considerable overlapping among them. As for example Regional Anatomy, Microscopic Anatomy and Developmental Anatomy all have their clinical aspects. The present study was designed to identify the distribution of weight in different aspects of Anatomy in the written exams of the undergraduate Anatomy course which will help to increase the objectivity of the exams and thus improve the teaching-learning process of Anatomy for the students as well as for the teachers. Written exams were targeted because analysis of assessment is a good way of providing an idea of the situation of the course and one valid way to do this is by analyzing the question papers.

Anatomy learning must be clinically meaningful because undergraduate MBBS course mainly produce clinicians and aim of present curriculum is to produce more competent doctors who will be able to meet the demand of the present health challenges of the society. To be a successful physician, one must know the normal and abnormal features of different aspects of Anatomy. As for example, for a physician, knowledge of Topographic Anatomy of kidney is necessary to explore it, however understanding the structure of filtration barrier is necessary to address the underlying cause of diabetes mellitus, students 
have to know the events of development and they should know how different congenital anomalies are developed to understand the congenital anomalies and its consequences. To examine the patient properly, the students have to know the Surface Anatomy of the kidney. Every structure, organ or system of the body should address all possible aspects of Anatomy and clinical correlation of all those aspects have to be reflected in the teaching and assessment system because that knowledge may be necessary to understand several disease processes of the same organ or system. Crowl mentioned that "in determining the content of an instructional unit; ask yourself not only what topics you have covered but also what proportion of the total content of each topic represents. What proportion of class time and textbook was devoted to each topic? When constructing your achievement test, make the proportion of the total number of test items dealing with each topic correspond to the proportion of the total content dealing with each topic ${ }^{8}$. This idea should be reflected in present undergraduate Anatomy course both in teaching-learning and in assessment system. Present curriculum ${ }^{1}$ set the learning objectives, teaching strategy and allocated marks for every aspects of Anatomy in oral and practical exams but written exams has no defined marks for different aspects of Anatomy. So it should be decided by the subject experts or teachers to increase the objectivity of the written exams of the MBBS Anatomy course.

In all reputed universities of the world, curricula of Anatomy course tends to be more functionally and clinically oriented and integrated where emphasis is given on practical aspects of the knowledge to increase the professional skill of the doctors. To meet the demand of the present day curricula, this approach is also accommodated by the standard textbooks of Anatomy. Amin felt that in recent textbooks of Cell Biology and Histology emphasis is given on structure-function correlation for betterunderstanding of the subject and importance is given on clinical correlation of the subject to improve the diagnostic and clinical abilities of the medical students ${ }^{9}$. In the present curriculum ${ }^{1}$ Cell biology and Histology has separate slot in oral, practical and written exams. In practical and oral exams specific marks are given for every topic of this subject, as for example, in oral exams, students may be asked about histological structures of 5 (five) viscera in soft part but which approach will be taken in asking questions that depend on the examiner's own judgement. Questions may judge mere factual information (only structures) or may address higher level of cognitive (understanding and applied) domain. Identification of slides in the light microscope has got emphasis in practical exams. So how to approach the different topics of the subject in oral exams are not defined. Practical exams emphasize on recall level of cognitive domain (to identify the slides under light microscope), so validity of these exams are low and they fail to follow the trends followed by the recent standard textbooks which change their presentation of the contents according to present concept and needs. In written exams, marks are not also given for General or Systemic Histology portion. There is also lacking regarding how to address the topic and that is true for every aspect of Anatomy included as content in the module ${ }^{3}$ and confusion may arise among examiners in giving weightage.

Adloki noticed that weightage to the content areas is a delicate issue on which even the experts often differ in opinion ${ }^{\mathbf{1 0}}$. It is evident from the question papers that different subdivisions of Anatomy (from Tables and figures of the result chapter) were less emphasized in the exams. These include Genetics, Radiographic Anatomy, Systemic Developmental Anatomy, Surface Anatomy and Clinical Anatomy. It is also found from result chapter that different subdivisions of Anatomy got variable amount of coverage in different regions of the body.Rubina ${ }^{5}$ also observed that some divisions of Anatomy were covered less than required which include Genetics, Histology, General Anatomy, General Developmental Anatomy, etc.

Developmental Anatomy are assessed both in oral and written exams and has no practical part. Like Cell biology and Histology this subdivision also 
suffered from lack of approach of asking questions in oral exams and there is chance of an examinee to pass without proper understanding of the subject which discourages deeper learning. Besides this, weightage on Developmental Anatomy in written exam is not clarified, so in different regions this aspect received different levels of coverage. In the curriculum ${ }^{1}$, broadly learning objectives for Developmental Anatomy are set and Uddin noted that the recent Developmental Anatomy textbooks incorporate new information and give importance on molecular and clinical aspects of Developmental Anatomy ${ }^{11}$. So assessment should be designed in such a way that it is compatible to meet the demand of the learning objectives and also reflects the trends present in the recent textbooks. Davis stated that the examination should be designed to assess the individual candidate's ability to meet the course objectives or curriculum outcomes and should cover the main contents of the course ${ }^{\mathbf{1 2}}$. Like Developmental Anatomy all aspects of Anatomy is treated similarly in the written assessment. On the other hand analyses of recent written question papers on Neuroanatomy revealed that $97 \%$ questions (segments)addressed 'recall-level' of cognitive domain in the public universities of Bangladesh (for SAQ and MCQ together) ${ }^{\mathbf{1 3}}$. This observation indicated gross violation of the suggestions of the module ${ }^{3}$. If questions fail to test higher level of cognitive domain, then student's learning will be deemed on factual knowledge retention and analytical ability and problem solving skill which are necessary for a doctor's professional life will be hampered.

Amin stated that though the efforts of medical educators to put emphasis on learning objectives as the driving force in a curriculum, a good and congruent examination system is equally important as the student's dedication to study is often triggered by this last factor ${ }^{14}$. As for example, if students learn the Anatomy of the nervous system, he will able to understand the clinical manifestations of cerebrovascular accident and it should be objective of the assessment system to ensure that the students are able to integrate the knowledge of Anatomy in their clinical years. So in written exams, proper weighatage in terms of marks allocation should be given to every aspects of Anatomy according to the learning objectives set by the curriulum ${ }^{1}$ and approach taken by recent textbooks to narrate those aspects of Anatomy.

\section{Conclusion}

The questions of the present written exams of the undergraduate Anatomy course lacks of proper weightage for different subdivisions of Anatomy which leads to variation of coverage of those subdivisions and hence decreases the validity of the exam.

\section{Recommendations}

To overcome the situation this study comes up with following suggestions:

1. To increase the validity of the written assessment proper weightage should be given to every subdivision of Anatomy in written exams and appropriate means should be selected for approaching the topic to be addressed in every subdivision to meet the objectives set by the present curriculum.

2. In oral and practical examinations although allocation of marks for different aspects of Anatomy is present in the module, but according to the learning objectives that are set in the curriculum $^{1}$ more congruent and appropriate means should be developed so that the course will be more transparent to the students as well as to the teachers which will lead to make more competent doctors for the country.

3. To bring these changes in depth interviews of key informants and focus group discussions can be arranged which may come up with suggestions to bring necessary changes in the present assessment system of undergraduate Anatomy course. 


\section{References}

1.Bangladesh Medical and Dental Council. Curriculum of Anatomy course for undergraduate medical students of Bangladesh-Compiled and edited by Center for Medical Education (CME). Dhaka: Bangladesh Medical and Dental Council; 2002. p 15-52.

2. Drake RL, Vogl W, Mitchell AW. Gray's Anatomy for students. 2nd ed. Philadelphia: Elsevier Churchill Livingstone; 2010. p xxiii.

3. University of Dhaka. Module on 1st Professional examination system to be held on January 2008 based on new curriculum. Dhaka: Core group, Faculty of Undergraduate Medicine, University of Dhaka. P 2-18.

4. Moore KL, Dally AF, Agur AMR. Clinically oriented anatomy. 6th ed. Philadelphia: Lippincott Williams \& Wilkins; 2010. p 2-4.

5. Sultana R, Shamim KM, Nahar L, Hasan F. Content validity of written examinations in undergraduate anatomy. Bangladesh journal of Anatomy 2009; 7 (1): 14-18.

6. Bannister LH, Berry MM, Collins P, Dyson M, Dussek JE, Fergnson MMJ. Gray's Anatomy: the anatomical basis of medicine and surgery. 38th ed. New York: Churchill Livingstone; 2005. p 1910.

7. Torato GJ. Principles of human anatomy. 8th ed. California:Benjamin /Cummings science publishing; 1999. p 2.

8. Crowl TK, Kaminsky S, Podell DM. Educational Psychlogy: Windows on teaching. 1st ed. Dabaque: Brown \& Benchmark; 1997. p.158-178.
9. Amin NF, Shamim KM. Trends in the presentation of Cell Biology and Histology in contemporary histology books as revealed in their 'Prefaces'. BSMMU Journal 2012; 5 (1): 46-54.

10. Adloki BV. Attributes of a good question paper. In: Sood R, chief editor. Assessment in medical education trends and tools. New Delhi: K.L. Wig Center for Medical Education and Technology; 1995. 73-6.

11. Uddin M, Shamim KM. Evolution in the presentation of Developmental Anatomy and Genetics in a commonly recommended developmental anatomy book through analyses it's 'Preface's. Bangladesh Journal of Anatomy 2011; 9 (1) 13-20.

12. Davis MH. Constructed response questions. In: Dent JA, Harden RM, editors. A practical guide for medical teachers. Edinburgh: Churchill Livingstone; 2001. 326-35.

13. Akter M. Analyses of the first professional MBBS written questions on Neuroanatomy and assessment of selected medical undergraduates' performances on illustration-based and clinically-oriented Neuroanatomy questions compared to non-illustration-based and non-clinically-oriented questions (Thesis). Dhaka: Bangabandhu Sheikh Mujib Medical University (BSMMU); $2010: 101$.

14. Amin Z. Basics in Medical Education. 1st ed. New Jersey: World Scientific; 2003. p. 62. 